\title{
NUMERICAL APPROACH FOR SIMULATING THE TENSIONING PROCESS OF COMPLEX PRESTRESSED CABLE-NET STRUCTURES
}

\author{
Deshen $\mathrm{CHEN}^{1}$, Yan ZHANG ${ }^{1,2^{\star}}$, Hongliang QIAN ${ }^{1}$, Huajie WANG ${ }^{1}$, Xiaofei JIN ${ }^{3}$ \\ ${ }^{1}$ School of Ocean Engineering, Harbin Institute of Technology at Weihai, Weihai, China \\ ${ }^{2}$ School of Civil Engineering/Key Laboratory of Structures Dynamic Behavior and Control of the Ministry of \\ Education, Harbin Institute of Technology, Harbin, China \\ ${ }^{3}$ China Construction First Building Group Corporation Limited, Beijing, China
}

Received 8 July 2021; accepted 10 September 2021

\begin{abstract}
The stability of cable-net structures depends on the prestress of the system. Due to the large displacement and mutual effect of the cables, it is difficult to simulate the tensioning process and control the forming accuracy. The Backward Algorithm (BA) has been used to simulate the tensioning process. The traditional BA involves complicated and tedious matrix operations. In this paper, a new numerical method based on the Vector Form Intrinsic Finite Element (VFIFE) method is proposed for BA application. Moreover, the tensioning sequence of a complex cable-net structure is introduced. Subsequently, a new approach for BA application in the simulation of the tensioning process is presented, which combines the VFIFE approach and the notion of form-finding. Finally, a numerical example is simulated in detail and the results of different tensioning stages are analyzed to verify the feasibility of the proposed approach. This study provides a significant reference for improving the construction control and forming accuracy of complex prestressed cable-net structures.
\end{abstract}

Keywords: tensioning process simulation, Backward algorithm, complex cable-net structure, computational method, Vector Form Intrinsic Finite Element.

\section{Introduction}

Prestressed cable-net structures are flexible space structures composed of interlaced steel cables. The prestressed steel cables can enhance the structure with stiffness and spatial stability, enabling the structure to bear external loads. The construction of prestressed cable-net structures is closely related to the tensioning process (Nazmy \& Abdel-Ghaffar, 2005; Cruz et al., 1998; Janjic et al., 2003). Due to limitations related to the tensioning machines and the working conditions faced on-site, cables may need to be tensioned in batches during the construction process. Thus, the application of prestress is an intricate process of force distribution and transmission. In addition, posttensioned cables affect the front-tensioned cables, and determining their relationship comes with difficulties.

Numerous studies have focused on specific structures, such as cable-stayed bridges (Dong et al., 2009; Reddy et al., 1999; Granata et al., 2018; Lozano-Galant et al., 2013) and domes (Gao et al., 2017; Liu et al., 2016). The main algorithms used in the literature to simulate the construction process are the Backward Algorithm (BA) and the Forward Algorithm (FA) (Lozano-Galant et al., 2012). The pretension obtained by the BA can avoid multiple adjustments, effectively improving the tensioning efficiency. Thus, the BA is a commonly used algorithm (Behin, 1990; Behin \& Murray, 1992; Wang et al., 2004). The first step of the $\mathrm{BA}$ is to design the structure in the prestressed equilibrium state, that is, the Objective Completion Stage (OCS) (Yang \& Sun, 1998; Mao et al., 1995). At this stage, the internal force and geometric state of the cables are regarded as the initial values. Then, the cables are removed in a backward sequence to determine the control parameters for each construction stage. Moreover, backward analysis can also determine the changes in the nodal displacement and internal force, achieving the same purpose as the FA. Therefore, a more satisfactory assessment and evaluation of the construction scheme can be performed, which can guide the construction and improve the construction technology.

In general, the traditional BA involves modeling using complex matrix operations. To obtain the control param-

*Corresponding author. E-mail: zyrrm@outlook.com 
eters of a certain stage, backward analysis is needed from its previous stage. For some complex cable-net structures, the convergence problem to be solved is always different. In 2004, Ting et al. (2004a, 2004b) and Shi et al. (2004) proposed a novel computational analysis approach named Vector Form Intrinsic Finite Element (VFIFE) method. This approach bears a novel calculation mode and describes, predicts, and analyzes the structural behavior through the motion of space particles. In the engineering field, the VFIFE method has exhibited good adaptability when dealing with strongly nonlinear problems. For example, Hou et al. (2018) derived the equation for 8-node hexahedral elements and applied it in spiral bevel gear meshing problems. Xu and Lin (2017) and Ye and Nian (2017) analyzed the rupture of dome structures and underground pipelines respectively. Li et al. (2018a, 2018b) analyzed the space nonlinear behavior of marine risers. Additionally, the VFIFE method has better convergence and accuracy characteristics, and is also suitable for parallel processing. Based on the core concept of the VFIFE method, convergence problems related to the simulation of the tensioning process of complex cable-net structures can be avoided.

In this study, a new approach without matrix operations is proposed, where the BA is applied to simulate the tensioning process of complex cable-net structures. To demonstrate the effectiveness and adaptability of the proposed approach, the Five-hundred-meter Aperture Spherical Telescope (FAST) active reflector, which is an extremely complex cable-net structure (Nan \& Peng, 2000), is selected as the simulation example. Such complex prestressed cable-net structures are mostly adopted for flexible reflectors and deployable antennas (Shi et al., 2021; Liu et al., 2019; Maddio et al., 2019; Yuan \& Yang, 2019; Li et al., 2016), where the construction accuracy has a direct impact on astronomical observation accuracy. The most critical tensioning process during the construction of such complex cable-net structures is simulated and the changes in the internal force are determined as well. This provides an innovative approach for the construction analysis of this type of complex prestressed cable-net structures.

\section{Complex cable-net structure of the FAST active reflector}

Figure 1 illustrates the complex cable-net structure of the FAST active reflector. The main cable-net is a major load-bearing structure attached to peripheral support. Each main cable node is connected to an actuator using a down-tied control cable, which controls the position of each node by modifying the cable length. Due to a large number of interlaced elements in the cable-net structure, complex forces emerge during the tensioning process.

The OCS of the FAST is the reference state of the reflector that serves as the BA initial state for the tensioning process simulation. Figure 2 presents the cross-sectional relationship of the reflector. In the reference state, the re-

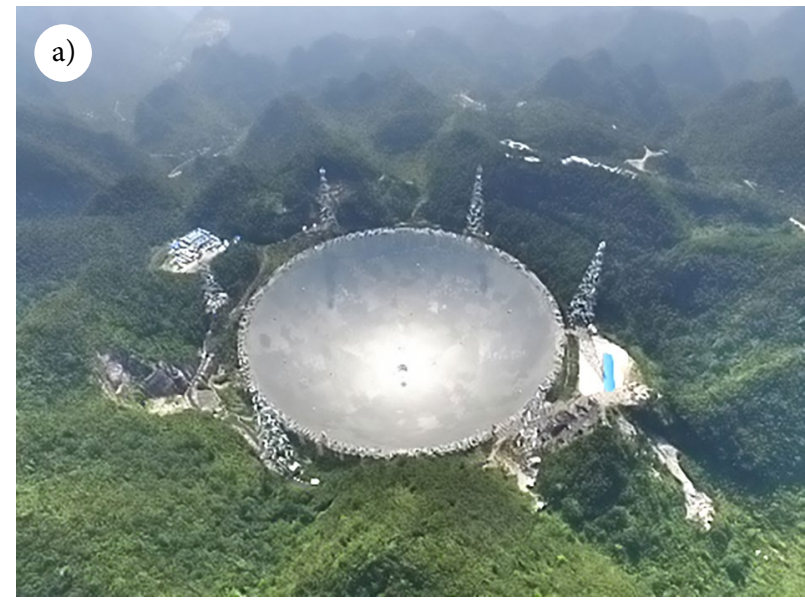

b)

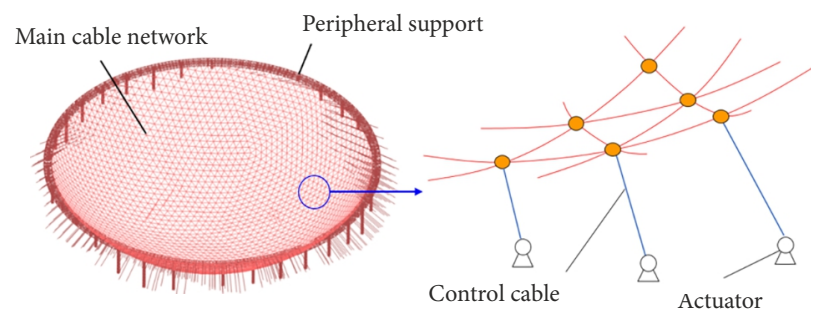

Figure 1. The complex cable-net structure of the FAST active reflector: a - Real image; b - Numerical model

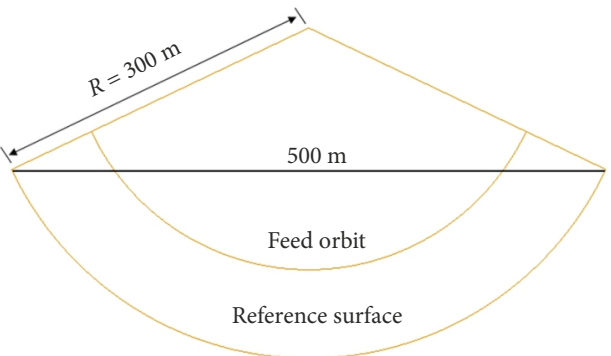

Figure 2. Reference surface of the cable-net structure

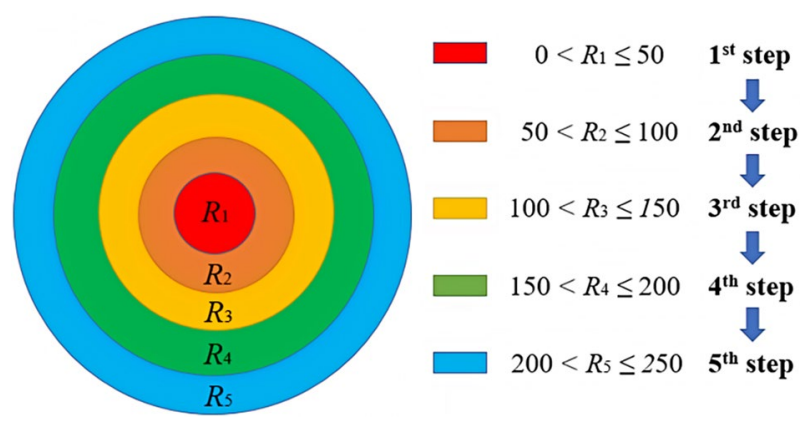

Figure 3. Tensioning arrangement diagram

flector is a defined spherical surface with a $500 \mathrm{~m}$ aperture and $300 \mathrm{~m}$ curvature radius.

During the construction process, the main cables are braided before installation. Subsequently, the actuator arms are extended, connecting the control cables with little or no tension. Finally, the cables are tensioned by changing the length of the actuators. Following the sym- 


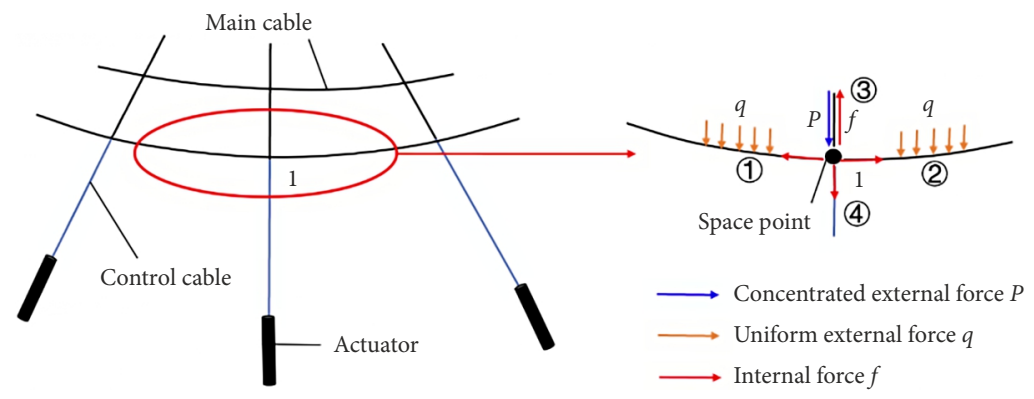

Figure 4. Description of a cable-net space point

metry principle, the tensioning unfolds in an inside-out fashion. The cables are connected and tensioned in five consecutive steps. Each step is ungraded and the actuators are directly tensioned into their place. The tensioning arrangement diagram is displayed in Figure 3.

\section{Novel simulation approach for the tensioning process}

\subsection{Structural discretization and motion description}

In the proposed VFIFE method, the complex cable-net structure is first discretized into mass particles and massless elements. The motion of particles is used to describe the motion of the structure, whereas the elements are utilized only in the internal force calculations. Consequently, the particles describe the structure and serve as the carriers of the spatial position, force, and deformation.

According to Figure 4, the node coordinates determine the position of the structure. The mass of the structure is assigned to the particles, and the internal and external forces exerted on the particles reflect the internal and external forces of the structure. Considering the space particle denoted with " 1 " in Figure 4, the internal force $f$ on point 1 results from the connected elements, while the external force stems from the concentrated external force $\boldsymbol{P}$ and the equivalent external force $\boldsymbol{F}_{\boldsymbol{q}}$ of the uniform external force $\boldsymbol{q}$. The internal force $\boldsymbol{f}$ is derived from the element deformation, which is related to the element material and cross-section, and can be determined using the material mechanics equation from strut-and-tie models.

When describing the motion of the structure nodes, their entire time history is discretized into a finite number of tiny time steps denoted by $\Delta t$. Subsequently, the actual trajectory of the space particles is described by superposing the motions in each micro-segment, thus approximating the continuous motion of space particles in both space and time. Formally, the time history can be represented as an interval $\left[t_{0}, t_{f}\right]$, and a series of time points $t_{0}, \ldots, t_{\alpha}, t_{\beta}$, $t_{\gamma}, \ldots, t_{f}$ divides the total time into subperiods. If the space particle motion in the period $\left[t_{\alpha}, t_{\beta}\right]$ meets the standard governing equation, the calculated trajectory of the space particle in this period is called a path element (Figure 5). A path element can undergo small deformation and large displacement. The physical properties of space particles

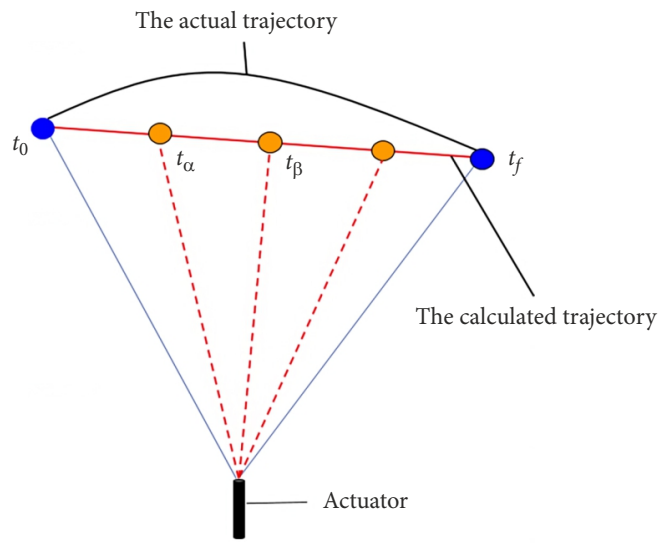

Figure 5. Schematic diagram of path elements

(e.g., material properties and stress states) are approximated as invariants in the path element. Therefore, many large displacement and deformation problems can be simplified into large displacement and small strain problems.

\subsection{Static equilibrium calculation principles}

The core of the VFIFE method is structural dynamic analysis. When the virtual damping force $\boldsymbol{F}_{D}$ acts as an energy dissipation mechanism, the amplitude of the space particles gradually decreases, converging eventually to a nearly stationary state, i.e., equilibrium. Once the virtual damping force $\boldsymbol{F}_{D}$ is added, the motion of the space particles is affected by the external force, internal force, and damping, consequently deforming the elements. On the contrary, the internal force generated by the deformation of the elements affects the connected space particles. The motion of the space particles follows Newton's second law, and generalized motion equations are given in Eqns (1) and (2):

$$
\begin{aligned}
& F_{D}=-\zeta m_{i} \dot{x} ; \\
& m_{i} \ddot{x}=F_{n}+F_{D}=P+f+F_{D},
\end{aligned}
$$

where $\zeta$ denotes the damping coefficient. In Eqns (1) and (2), the damping coefficient serves solely as an energy dissipation mechanism. It can be equal to an actual material damping for dynamic problems or an arbitrary positive value can be assumed for the sake of numerical calculation. The damping coefficient does not affect the final convergence result but it affects the convergence speed. 
Parameters $x, \dot{x}$, and $\ddot{x}$ denote the space particles' displacement vector, velocity vector, and acceleration vector, respectively. $\boldsymbol{P}$ denotes the external force on space particles, $\boldsymbol{f}$ denotes the internal force on space particles, and $F_{n}$ denotes the resultant force vector of the particle, excluding the virtual damping force, $F_{n}=\left[F_{x}, F_{y}, F_{z}\right]$.

Equation (1) can be solved in many different ways. In this paper, the explicit central difference method is employed, which does not require complex iterations and is simpler than other traditional methods. Both $\boldsymbol{x}$ and $F_{n}$ are functions of time $t, t=t_{n}=n h(n \geq 0)$, where $h$ is the time step increment and $n=0$ is the initial step. The velocity vector $\dot{x}_{n}$ and acceleration vector $\ddot{x}$ of each particle can be respectively obtained by:

$$
\begin{aligned}
& \dot{x}_{n}=\left(x_{n+1}-x_{n-1}\right) / 2 h ; \\
& \ddot{x}_{n}=\left(x_{n+1}-2 x_{n}+x_{n-1}\right) / h^{2},
\end{aligned}
$$

where $x_{n-1}, x_{n}$, and $x_{n+1}$ denote the particle displacement vectors at time steps $(n-1), n$, and $(n+1)$.

Equations (1) to (4) yield the particle motion difference expressed as:

$$
\left\{\begin{array}{ll}
x_{1}=h^{2} F_{0} / 2 m_{i}+h(1-\zeta h / 2) \dot{x}_{0}+x_{0} & n=0 \\
x_{n+1}=\left(h^{2} F_{n} / m_{i}+2 x_{n}-c_{2} x_{n-1}\right) / c_{1} & n \geq 1
\end{array},\right.
$$

where the coefficients are set as follows:

$$
\begin{aligned}
& c_{1}=1+\zeta h / 2 ; \\
& c_{2}=1-\zeta h / 2 .
\end{aligned}
$$

The particle motion difference equations are independent (i.e., they do not affect each other). Consequently, the matrix singularity problems are avoided and nonconvergence due to matrix operations in the traditional $\mathrm{BA}$ is prevented.

\subsection{Novel backward algorithm}

When a structure is subjected to large deformations in the tensioning process, its post-tensioning state is usually obtained first. The BA is an effective approach for determining the zero state of a structure. Starting from the post-tensioning state, the structure tensioning process is simulated backward. In structures that require tensioning a large number of cables, the cables are added following a tensioning sequence. Conversely, the BA gradually removes these cables from structures. Therefore, the tensioning process comprises numerous distinct intermediate states. When analyzing the tensioning stage $k$, the traditional BA relies on the form and stress state of the structure at the tensioning stage $k+1$. Nevertheless, using form-finding, the target tensioning stage can be analyzed directly, which is more convenient. The flow chart of the proposed novel BA is illustrated in Figure 6.

As it can be seen in Figure 6, the form and stress state of the cable-net structure at the OCS is obtained first. Using the element introduction and removal concept, the cables corresponding to the $5^{\text {th }}$ step (Figure 3) are omitted from the structure according to the backward sequence of the tensioning process. Similarly, the strain, load, mass, and other relevant effects of the cables are set to zero. The internal force of the removed cables reacts on the remaining structure, inducing additional internal force and deformation. Then, the VFIFE method is used to determine the equilibrium state. This process is iterative, requiring 200 iterations to get satisfactory results. Hence, the tensioned structure and stress state after the $4^{\text {th }}$ step are obtained. The above-described procedure is repeated, gradually removing the cables in the $4^{\text {th }}, 3^{\text {rd }}, 2^{\text {nd }}$, and $1^{\text {st }}$ steps until the zero state of the complex cable-net structure is found. The internal force and deformation state of the structure in each tensioning stage serve as an essential basis for guiding the construction.

\section{Tensioning process simulation}

\subsection{Numerical model}

The numerical model of the complex FAST active reflector cable-net structure contained 2590 main cable nodes denoted as J1 to J2590. Similarly, the main cables were labeled as M1 to M6980, and a total of 2275 control cables were denoted as $\mathrm{C} 1$ to $\mathrm{C} 2275$. The diameter of the main cables was $25 \mathrm{~mm}$ and that of the control cables was $10 \mathrm{~mm}$. The elastic modulus E was 2.05 MPa (Qian, 2007).

In the work reported by Qian (2007), the OCS of the cable-net structure was obtained using the traditional finite element method. Subsequently, the OCS was reconstructed using the new VFIFE method, and a comparison of the OCS stress nephogram is presented in Figure 7. Because the novel BA based on the VFIFE method avoids complex matrix operations compared to the traditional FE methods, it is characterized by an improved convergence. In the OCS obtained by the VFIFE method, the main cable stress ranges between 465.25 and $576.73 \mathrm{MPa}$, while the stress obtained using the traditional finite element method varies from 469.22 to $570.78 \mathrm{MPa}$. In Figure 8, the stress distribution comparison and error rate are exhibited. Despite that the two nonlinear methods have distinct form-finding principles and different iteration steps, the maximum error rate of the main cable stress is only $3.29 \%$. In both simulation results, the main cable nodes can be guaranteed to be on the reference surface. These results verify the correctness and feasibility of the VFIFE method.

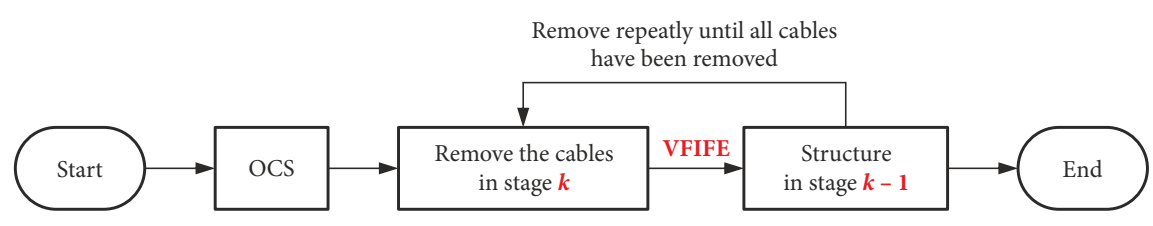

Figure 6. Flow chart of the novel backward algorithm 

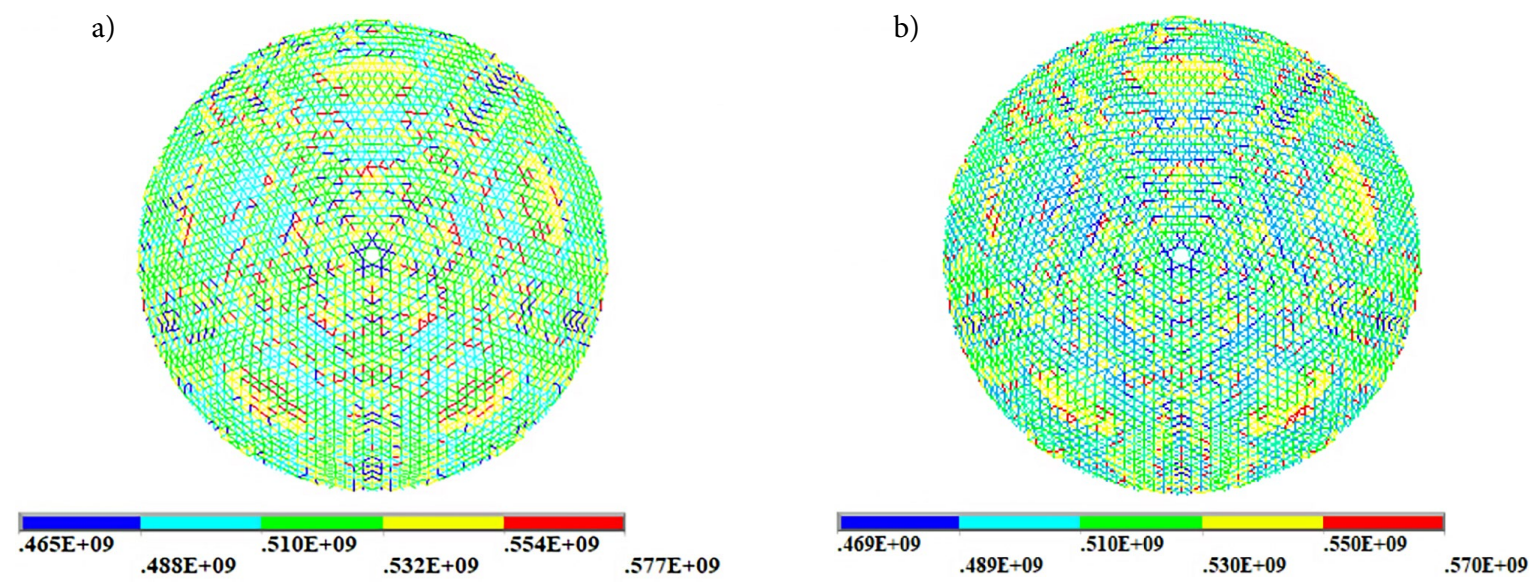

Figure 7. OCS stress nephogram obtained by different methods: a - Novel VFIFE method; b - Traditional finite element method

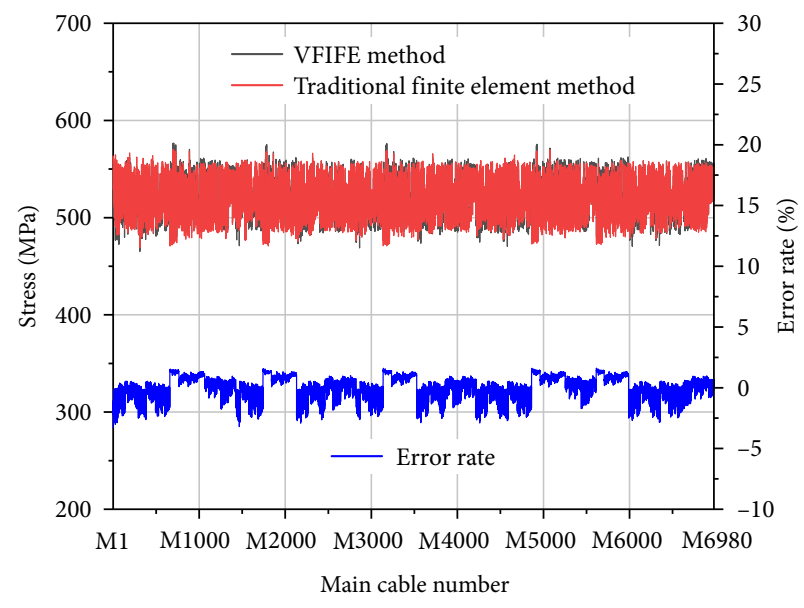

Figure 8. Comparison of the main cable stress distribution

\subsection{Cable-net structure at different tensioning stages}

As described in Section 2, the tensioning process takes place from the inside outwards, and the cables are connected and tensioned in five consecutive steps. In backward analysis, the tensioning process is simulated in reverse order, i.e., inwards. Main cables and the corresponding control cables are removed in batches to determine the internal force and deformation state of the structure in each tensioning stage. The omitted control cables in the different tensioning stages are listed in Table 1 . The state in which all control cables have been removed denotes the zero state.

Table 1. Removed control cables in the different tensioning stages

\begin{tabular}{|l|c|}
\hline \multicolumn{1}{|c|}{ Stage } & Removed control cables \\
\hline $5^{\text {th }}$ step $(\mathrm{OCS}) \rightarrow 4^{\text {th }}$ step & C1281 $\sim$ C2275 \\
\hline $4^{\text {th }}$ step $\rightarrow 3^{\text {rd }}$ step & C706 C1281 \\
\hline $3^{\text {rd }}$ step $\rightarrow 2^{\text {nd }}$ step & C301 C706 \\
\hline $2^{\text {nd }}$ step $\rightarrow 1^{\text {st }}$ step & C71 C301 \\
\hline $1^{\text {st }}$ step $\rightarrow$ Zero state & C1 $\sim$ C71 \\
\hline
\end{tabular}

Figure 9 illustrates the stress nephogram of the complex cable-net structure at different tensioning stages while reflecting the removed control cables in each stage. The stress extremum in different tensioning stages is depicted in Figure 10. In the zero state, the maximum main cable stress is equal to $297.12 \mathrm{MPa}$. During the first step, the maximum stress value increases to $592.53 \mathrm{MPa}$, with $0.143 \%$ of the main cables' stress exceeding the maximum stress in OCS. The subsequent steps further increase the proportion of the main cables whose stress exceeds the maximum OCS value. In particular, $0.229 \%$ of the main cables' stress exceeds the maximum stress in OCS after the $2^{\text {nd }}$ step, $0.287 \%$ after the $3^{\text {rd }}$ step, and $1.877 \%$ after the $4^{\text {th }}$ step. Starting from the $2^{\text {nd }}$ step, the maximum stress gradually increases from $651.50 \mathrm{MPa}$ after the $2^{\text {nd }}$ to $770.93 \mathrm{MPa}$ after the $4^{\text {th }}$ step. The main cables with maximum stress in each tensioning stage are those near the edge of the beam truss. During the entire tensioning process, the main cable stress is within the safety margin, and no relaxation occurs.

The internal force distribution of the control cables is demonstrated in Figure 11. Trends similar to those observed for the main cables can be seen in control cable case as well. First, the number of control cables whose stress exceeds the maximum OCS stress increases, and, after the $4^{\text {th }}$ step, $1.714 \%$ of control cables' stress exceeds the maximum. Secondly, the control cable maximum stress rises from $161.631 \mathrm{MPa}$ after the $1^{\text {st }}$ step to $433.228 \mathrm{MPa}$ after the $4^{\text {th }}$ step. In the $3^{\text {rd }}$ and $4^{\text {th }}$ steps, the control cables with maximum stress are near the beam truss edge. Finally, throughout the entire tensioning process, the control cables' stress remains within the safety margin without any relaxation. Thus, the tensioning scheme can be considered feasible.

The obtained results verify the feasibility of the proposed BA based on the VFIFE method. Due to the numerous cross nodes and complex stress characteristics, the obtained zero state of the structure enables strict control of the fabrication length of each cable, improves the overall accuracy, and avoids the need for length adjustments during installation. 
a)

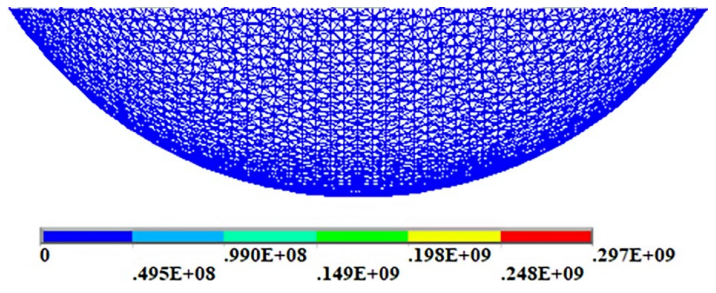

c)

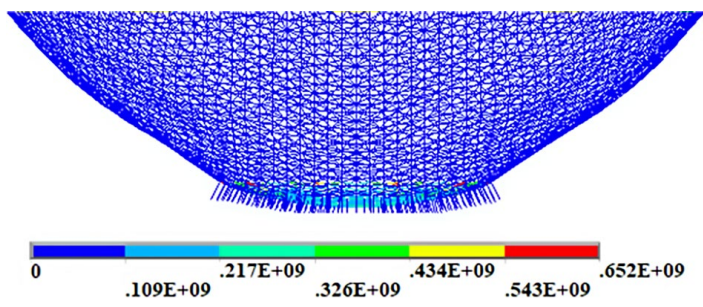

e)

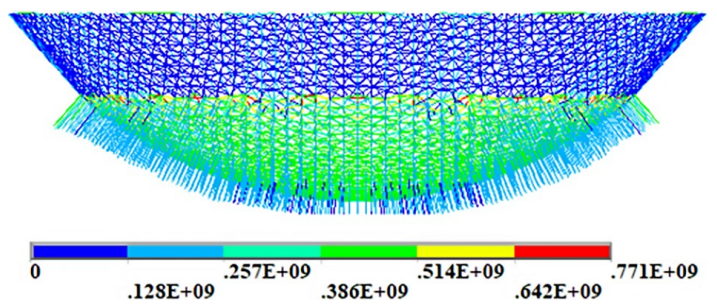

b)

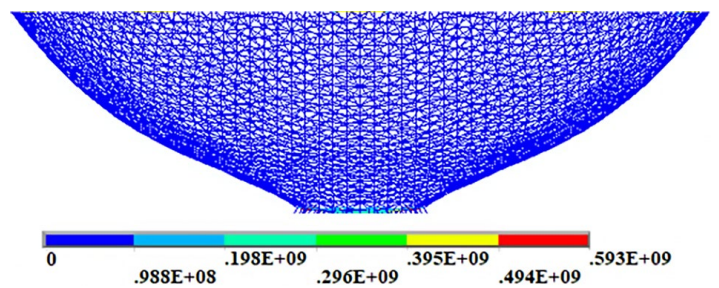

d)

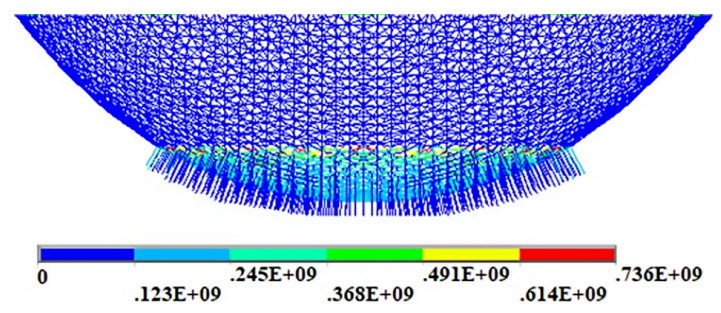

f)

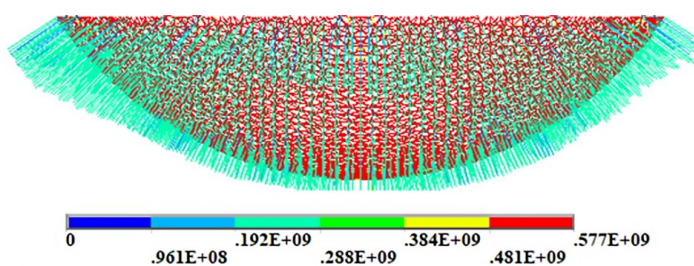

Figure 9. Stress nephogram at different tensioning stages:

$\mathrm{a}-$ Zero state; $\mathrm{b}-1^{\text {st }}$ step; $\mathrm{c}-2^{\text {nd }}$ step; $\mathrm{d}-3^{\text {rd }}$ step; $\mathrm{e}-4^{\text {th }}$ step; $\mathrm{f}-5^{\text {th }}$ step (OCS)

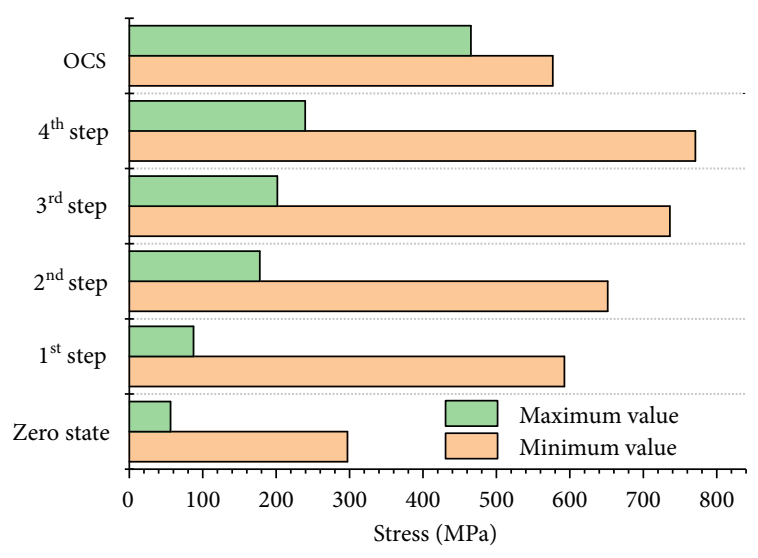

Figure 10. Stress extremum for different tensioning stages

\section{Conclusions}

The tensioning and forming processes of cable-net structures are highly complicated. However, they are critical for ensuring construction safety and compliance with the design requirements. In this study, a novel BA is proposed and its feasibility is demonstrated based on the numerical example of the complex cable-net structure of the FAST active reflector. The key findings of this work can be summarized as follows:

1) A new BA based on the VFIFE method has been proposed building on the idea of form-finding. This approach results in the independent particle motion equations, thus rendering it convenient for element removal and avoiding the complex matrix operation.

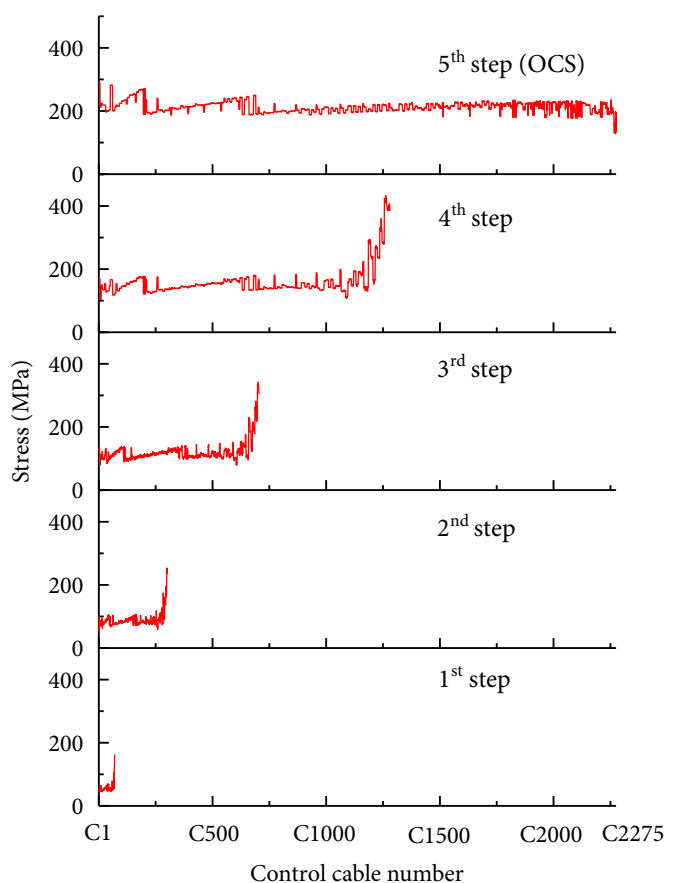

Figure 11. Stress distribution of control cables for different tensioning stages

2) The VFIFE method can be readily used in the OCS simulation. The maximum error rate of the stress estimated by the VFIFE method and traditional finite element method is only $3.29 \%$. In both simulation results, the main cable nodes are guaranteed to be on the reference surface. These results verify the correctness and feasibility of the proposed VFIFE method. 
3) In the backward analysis of the tensioning process, the maximum main cable stress occurs after the $4^{\text {th }}$ step when $1.877 \%$ of the main cables' stress exceeds the maximum stress in the OCS. The main cables with maximum stress are those near the beam truss edge. During the entire tensioning process, the stress of the main cables is within the safety margin, and no relaxation occurs.

4) The maximum stress in control cables also occurs after the $4^{\text {th }}$ step, and $1.714 \%$ of control cables' stress exceeds the maximum stress in OCS. Similar to findings related to main cables, the stress of the control cables remains within the safety margin, and no relaxation occurs. The final structure at the zero state provides an important basis for the accurate control of blanking and forming.

The novel BA based on the VFIFE method represents an effective approach for simulating the construction process. Its characteristics of no complex matrix operations and improved convergence show the potential for application in other prestressed structures, such as truss string structures, latticed shell string structures and cable-stayed bridges. However, since this method needs a little more computational cost, its efficiency will be investigated in detail in the future.

\section{Funding}

This work was supported by the $<$ National Natural Science Foundation of China> under Grant [number 51808168 and 51678191]; <General Program of Natural Science Foundation of Shandong Province> under Grant [number ZR2019MEE047].

\section{Author contributions}

DC and HQ conceived the study. DC and YZ were responsible for the design and development of the data analysis. DC, YZ and XJ were responsible for data collection and analysis. DC and YZ were responsible for data interpretation. DC wrote the first draft of the article. HQ and HW were responsible for funding acquisition. HW and XJ were responsible for supervision.

\section{Disclosure statement}

The authors declare that they have no conflict of interest. All the funding sources have been disclosed and are acknowledged in the manuscript.

\section{References}

Behin, Z. (1990). Erection analysis of cable-stayed bridges $[\mathrm{PhD}$ dissertation]. University of Alberta, Edmonton, Canada.

Behin, Z., \& Murray, D. W. (1992). A substructure-frontal technique for cantilever erection analysis of cable-stayed bridges. Computers \& Structures, 42(2), 145-157.

https://doi.org/10.1016/0045-7949(92)90200-J
Cruz, P. J. S., Mari, A. R., \& Roca, P. (1998). Nonlinear timedependent analysis of segmentally constructed structures. Journal of Structural Engineering, 124(3), 278-287. https://doi.org/10.1061/(ASCE)0733-9445(1998)124:3(278)

Dong, X., Bin, C., \& Lei, L. (2009). Tensioning process of Sanhao arch pylon cable-stayed bridge. Iabse Symposium Report, 96(11), 49-56. https://doi.org/10.2749/222137809796078306

Gao, Z., Xue, S., \& Wang, T. (2017). Four-step tensioning construction method and experimental study for rigid bracing dome. International Journal of Steel Structures, 18(1), 281291. https://doi.org/10.1007/s13296-017-1002-6

Granata, M. F., Longo, G., Recupero, A., \& Arici, M. (2018). Construction sequence analysis of long-span cable-stayed bridges. Engineering Structures, 174, 267-281.

https://doi.org/10.1016/j.engstruct.2018.07.064

Hou, X., Fang, Z., \& Zhang, X. (2018). Static contact analysis of spiral bevel gear based on modified VFIFE (vector form intrinsic finite element) method. Journal of Engineering Mechanics, 60, 192-207. https://doi.org/10.1016/j.apm.2018.03.021

Janjic, D., Pircher, M., \& Pircher, H. (2003). Optimization of cable tensioning in cable-stayed bridges. Journal of Bridge Engineering, 8(3), 131-137. https://doi.org/10.1061/(ASCE)1084-0702(2003)8:3(131)

Li, P., Liu, C., Tian, Q., Hu, H., \& Song, Y. (2016). Dynamics of a deployable mesh reflector of satellite antenna: Form-finding and modal analysis. Journal of Computational and Nonlinear Dynamics, 11(4), 041017. https://doi.org/10.1115/1.4033440

Li, X., Guo, X., \& Guo, H. (2018a). Vector form intrinsic finite element method for nonlinear analysis of three-dimensional marine risers. Ocean Engineering, 161, 257-267.

https://doi.org/10.1016/j.oceaneng.2018.05.009

Li, X., Guo, X., \& Guo, H. (2018b). Vector form intrinsic finite element method for the two-dimensional analysis of marine risers with large deformations. Journal of Ocean University of China, 17(3), 498-506.

https://doi.org/10.1007/s11802-018-3340-1

Liu, H., Zhang, W., Yuan, H., Jin, Z., \& Zheng, J. (2016). Modified double-control form-finding analysis for suspendomes considering the construction process and the friction of cable-strut joints. Engineering Structures, 120, 75-81. https://doi.org/10.1016/j.engstruct.2016.04.023

Liu, R., Guo, H., Liu, R., Tang, D., Wang, H., \& Deng, Z. (2019). Design and form finding of cable net for a large cable-rib tension antenna with flexible deployable structures. Engineering Structures, 199(15), 109662.

https://doi.org/10.1016/j.engstruct.2019.109662

Lozano-Galant, J. A., Payá-Zaforteza, I., Dong, X., \& Turmo, J. (2012). Forward Algorithm for the construction control of cable-stayed bridges built on temporary supports. Engineering Structures, 40, 119-130.

https://doi.org/10.1016/j.engstruct.2012.02.022

Lozano-Galant, J. A., Dong, X., Payá-Zaforteza, I., \& Turmo, J. (2013). Direct simulation of the tensioning process of cablestayed bridges. Computers \& Structures, 121, 64-75. https://doi.org/10.1016/j.compstruc.2013.03.010

Maddio, P. D., Meschini, A., Sinatra, R., \& Cammarata, A. (2019). An optimized form-finding method of an asymmetric large deployable reflector. Engineering Structures, 181, 27-34. https://doi.org/10.1016/j.engstruct.2018.11.077

Mao, C. S., Du, G. H., \& Fan, L. C. (1995). A backward analysis with creep effect for concrete cable-stayed bridges. China Journal of Highway and Transport, 8(1), 42-46 (in Chinese). 
Nan, R., \& Peng, B. (2000). A Chinese concept for the $1 \mathrm{~km}^{2}$ radio telescope. Acta Astronautica, 46, 667-675. https://doi.org/10.1016/S0094-5765(00)00030-8

Nazmy, A. S., \& Abdel-Ghaffar, A. M. (2005). Three-dimensional nonlinear static analysis of cable-stayed bridges. Computers \& Structures, 34(2), 257-271. https://doi.org/10.1016/0045-7949(90)90369-D

Qian, H. (2007). Theoretical and experimental research on supporting structure of FAST reflector [PhD dissertation]. Harbin Institute of Technology, Harbin, China.

Reddy, P., Ghaboussi, J., \& Hawkins, N. M. (1999). Simulation of the construction of cable-stayed bridges. Journal of Bridge Engineering, 4(4), 249-257. https://doi.org/10.1139/197-109

Shi, C., Guo, H., Cheng, Y., Liu, R., \& Deng, Z. (2021). Design and multi-objective comprehensive optimization of cablestrut tensioned antenna mechanism. Acta Astronautica, 178, 406-422. https://doi.org/10.1016/j.actaastro.2020.09.031

Shi, C., Wang, Y. K., Ting, E. C. (2004). Fundamentals of a vector form intrinsic finite element: Part III. Convected material frame and examples. Journal of Mechanics, 20, 133-143. https://doi.org/10.1017/S172771910000335X

Ting, E. C., Shi, C., \& Wang, Y. K. (2004a). Fundamentals of a vector form intrinsic finite element: Part I. Basic procedure and a planar frame element. Journal of Mechanics, 20, 113122. https://doi.org/10.1017/S1727719100003336

Ting, E. C., Shi, C., \& Wang, Y. K. (2004b). Fundamentals of a vector form intrinsic finite element: Part II. Plane solid element. Journal of Mechanics, 20, 123-132. https://doi.org/10.1017/S1727719100003348

Wang, P. H., Tang, T. Y., \& Zheng, H. N. (2004). Analysis of cable-stayed bridges during construction by cantilever methods. Computers \& Structures, 82(4-5), 329-346. https://doi.org/10.1016/j.compstruc.2003.11.003

Xu, L., \& Lin, M. (2017). Analysis of buried pipelines subjected to reverse fault motion using the vector form intrinsic finite element method. Soil Dynamics and Earthquake Engineering, 93, 61-83. https://doi.org/10.1016/j.soildyn.2016.12.004

Yang, B., \& Sun, M. (1998). Cable tensions for cable-stayed bridges and optimized nonlinear back-running analysis. China Journal of Highway and Transport, 3, 57-63 (in Chinese).

Ye, J., \& Nian, Q. (2017). Progressive collapse simulation based on DEM for single-layer reticulated domes. Journal of Constructional Steel Research, 128, 721-731. https://doi.org/10.1016/j.jcsr.2016.09.025

Yuan, S., \& Yang, B. (2019). The fixed nodal position method for form finding of high precision lightweight truss structures. International Journal of Solids and Structures, 161, 82-95. https://doi.org/10.1016/j.ijsolstr.2018.11.011 